\title{
Paucisalibacillus globulus gen. nov., sp. nov., a Gram-positive bacterium isolated from potting soil
}

Correspondence

António Veríssimo

averiss@ci.uc.pt

\author{
Inês Nunes, ${ }^{1}$ Igor Tiago, ${ }^{1}$ Ana Luísa Pires, ${ }^{1}$ Milton S. da Costa ${ }^{2}$ \\ and António Veríssimo ${ }^{1}$
}

Departamento de Zoologia and Centro de Neurociências de Biologia Celular ${ }^{1}$ and Departamento de Bioquímica and Centro de Neurociências de Biologia Celular², Universidade de Coimbra, 3004-517 Coimbra, Portugal
Gram-positive, rod-shaped, aerobic or facultatively anaerobic, spore-forming bacteria that grow optimally in media containing $\mathrm{NaCl}$ are assigned to 18 genera within the family Bacillaceae that have similar characteristics and some close phylogenetic relationships. Four of these genera, namely Salinibacillus (Ren \& Zhou, 2005), Virgibacillus (Heyndrickx et al., 1998), Oceanobacillus (Lu et al., 2001) and Lentibacillus (Yoon et al., 2002), form a coherent phylogenetic cluster. During an investigation of the presence of Legionella in composts and potting soils used in Portugal, several slightly halophilic Gram-positive bacteria were isolated and further characterized. One of these isolates shared many physiological and biochemical characteristics with species of the genera mentioned above, but had a distinctly lower $\mathrm{NaCl}$ requirement for optimal growth and a distinctive peptidoglycan composition. Furthermore, 16S rRNA gene sequence analysis showed that this organism represents a distinct phylogenetic lineage within the family Bacillaceae. In this study, the morphological, physiological, chemotaxonomic and phylogenetic characteristics of strain $\mathrm{B} 22^{\mathrm{T}}$ are described.

The GenBank/EMBL/DDBJ accession number for the $16 \mathrm{~S}$ rRNA gene sequence of strain $B 22^{\top}$ is $A M 114102$.
Strain $\mathrm{B} 22^{\mathrm{T}}$ was isolated from potting soil on buffered charcoal yeast extract (BCYE) medium (Edelstein, 1981), which is normally used for the isolation and growth of Legionella spp. Cultures were purified by subculturing and preserved at $-70{ }^{\circ} \mathrm{C}$ in $5 \%$ yeast extract medium with $15 \%$ glycerol. Despite the organism having been isolated on BCYE, the strain was routinely cultured at $37^{\circ} \mathrm{C}$ in alkaline buffered medium 2 (ABM2) with $1 \% \mathrm{NaCl}$, adjusted to pH 8.0 (Tiago et al., 2005b). Unless otherwise stated, all morphological examinations and biochemical and tolerance tests were performed on this medium after up to 6 days incubation as described previously (Tiago et al., 2005b). The growth temperature range of the strain was examined in liquid medium in a reciprocal water bath between 20 and $45^{\circ} \mathrm{C}$. The $\mathrm{NaCl}$ range for growth of the organism was determined at $\mathrm{pH} 8.0$ and $37^{\circ} \mathrm{C}$. The $\mathrm{pH}$ range for growth was determined at $37^{\circ} \mathrm{C}$ in the same medium buffered at $\mathrm{pH}$ values between $\mathrm{pH} 6.0$ and 9.5 as described previously (Tiago et al., 2005b). Anaerobic growth was assessed at $37^{\circ} \mathrm{C}$ in anaerobic chambers with an $\mathrm{H}_{2} / \mathrm{CO}_{2}$ atmosphere (bioMérieux). Single carbon source assimilation tests were performed in $20 \mathrm{ml}$ screw-capped tubes as described previously (Tiago et al., 2005a). Acid production from carbohydrates was also determined using API $50 \mathrm{CH}$ test 
strips (Analytab Products; bioMérieux) containing 50 $\mathrm{CHB} / \mathrm{E}$ medium, as described previously (Tiago et al., 2006). Peptidoglycan analysis was performed according to Schleifer (1985) and Schleifer \& Kandler (1972). Respiratory quinone analysis was performed according to Tindall (1989) and the fatty acid profile was determined as described by Tiago et al. (2005b) using the standard MIS library Generation Software (Microbial ID).

The DNA $\mathrm{G}+\mathrm{C}$ content was determined by HPLC as described by Mesbah et al. (1989). The $16 \mathrm{~S}$ rRNA gene was sequenced as described by Tiago et al. (2006). Phylogenetic analysis was performed using the ARB software package (Ludwig et al., 2004). Phylogenetic trees were constructed using maximum-likelihood (Felsenstein, 1981) and neighbour-joining (Saitou \& Nei, 1987) algorithms. Tree topologies were evaluated by performing bootstrap analysis (Felsenstein, 1985) of a dataset of 1000.

Strain $\mathrm{B} 22^{\mathrm{T}}$ formed small, beige-coloured, spherical colonies. Cells were Gram-positive, motile by two polar flagella and rod-shaped $(0 \cdot 5 \mu \mathrm{m}$ in width by $3 \cdot 0-7 \cdot 0 \mu \mathrm{m}$ in length), with oval terminal endospores in a non-swollen sporangium. The $\mathrm{NaCl}$ concentration for optimum growth was $1.0 \%$, but growth occurred in the absence of $\mathrm{NaCl}$ and in medium containing up to $8.0 \% \mathrm{NaCl}$. Strains belonging to the phylogenetically most related genera had higher $\mathrm{NaCl}$ requirements for optimal growth and they could grow at much higher $\mathrm{NaCl}$ concentrations. Moreover, only species of the genus Oceanobacillus and strain $\mathrm{B} 22^{\mathrm{T}}$ were able to grow in media without $\mathrm{NaCl}$ (Table 1). The novel organism also had a narrower $\mathrm{pH}$ range $(\mathrm{pH} 7 \cdot 0-9 \cdot 0)$ for growth when compared with members of related genera. Strain $\mathrm{B} 22^{\mathrm{T}}$ did not reduce nitrate. Casein, starch, DNA, arbutin, aesculin, hippurate, elastin, gelatin and Tweens 20, 40,60 and 80 were hydrolysed, but xylan and urea were not. Furthermore, B22 ${ }^{\mathrm{T}}$ utilized several sugars and proteinaceous substrates.

Strain $\mathrm{B} 22^{\mathrm{T}}$ had peptidoglycan type A4 $\alpha$; L-Lys was the diamino acid at position 3 of the peptidoglycan and the dicarboxylic amino acid present in the cross-linkage was D-Asp. The peptidoglycan composition of the novel strain is unique amongst members of phylogenetically related genera, which are characterized by direct cross-linkage between positions 3 and 4 and by the presence of meso-diaminopimelic acid as diamino acid (Table 1). Menaquinone-7 (MK-7) was the major respiratory quinone detected. The fatty acid composition of strain $\mathrm{B} 22^{\mathrm{T}}$ was characterized by the predominance of branched fatty acids, namely anteiso-15:0, anteiso-17:0 and iso-15:0, which made up $58 \cdot 9,18 \cdot 3$ and $15 \cdot 4 \%$ of the total fatty acids, respectively (Table 2 ).

The DNA G + C content of strain $\mathrm{B} 22^{\mathrm{T}}$ was 37.9 mol\%. Comparative analyses of $1547 \mathrm{nt}$ positions of the $16 \mathrm{~S}$ rRNA gene sequence of strain $\mathrm{B} 22^{\mathrm{T}}$ with those of other members of the Bacillaceae lineage showed that strain $\mathrm{B} 22^{\mathrm{T}}$ had a close relationship ( $98 \%$ similarity) with a clone sequence recovered from an aerosol in an urban environment (GenBank accession no. DQ129343). The cultured and described taxa to which strain $\mathrm{B} 22^{\mathrm{T}}$ showed the closest $16 \mathrm{~S}$ rRNA gene sequence similarity were species of the genera Salinibacillus $(94 \cdot 3-94 \cdot 7 \%)$, Virgibacillus $(92 \cdot 8-95 \cdot 1 \%)$, Oceanobacillus $(93 \cdot 2-94 \cdot 7 \%)$ and Lentibacillus $(92 \cdot 3-$ $93 \cdot 1 \%)$. The novel isolate and these genera formed a coherent cluster supported by bootstrap analysis at a confidence level of $71 \%$, thus showing the phylogenetic relatedness of this cluster (Fig. 1). Furthermore, this tree topology was found using the maximum-likelihood as well as the neighbour-joining algorithms.

The knowledge of bacteria of the family Bacillaceae that grow optimally in media containing $\mathrm{NaCl}$ has increased of late and, despite the fact that these organisms share similar characteristics and close phylogenetic relationships, a number of new genera have been described recently. Nevertheless, strain $\mathrm{B} 22^{\mathrm{T}}$ can be clearly distinguished from the type strains of species of closely related genera, namely by the $\mathrm{NaCl}$ requirement for growth, the peculiar peptidoglycan composition present in the cell wall and the relative amounts of the major fatty acid components, in addition to other phenotypic features.

On the basis of these findings, it is proposed that strain $\mathrm{B} 22^{\mathrm{T}}$ represents a novel species in a new genus, Paucisalibacillus globulus gen. nov., sp. nov.

\section{Description of Paucisalibacillus gen. nov.}

Paucisalibacillus (Pau'ci.sa.li.ba.cil'lus. L. adj. paucus few, little; L. n. sal, salis salt; L. masc. n. bacillus a small staff, a wand; N.L. masc. n. Paucisalibacillus a rod that needs only small amounts of salt).

Form rod-shaped cells, which stain Gram-positive, are motile by means of two polar flagella at one end and sporeforming. Strictly aerobic, oxidase-negative and catalasepositive. $\mathrm{NaCl}$ is not required for growth; small amounts of $\mathrm{NaCl}$ improve growth. Peptidoglycan is of the A4 $\alpha$ type with L-Lys as the diamino acid and D-Asp as the dicarboxylic amino acid present in the cross-linkage. Major respiratory quinone is MK-7. Fatty acids are predominantly saturated and branched. Belongs to the family Bacillaceae. The type species is Paucisalibacillus globulus.

\section{Description of Paucisalibacillus globulus sp. nov.}

Paucisalibacillus globulus [glo'bu.lus. L. n. globulus (nominative in apposition) a little ball, a globule, because the bacterium forms colonies that are similar to a little ball, a globule].

Exhibits the following characteristics in addition to those described for the genus. Cells are $0.5 \mu \mathrm{m}$ in width by $3 \cdot 0-7 \cdot 0 \mu \mathrm{m}$ in length. Oval endospores are formed in a terminal non-swollen sporangium. Heterotrophic. Colonies are small, smooth, spherical and beige-coloured. The 
Table 1. Comparison of characteristics of strain B22 ${ }^{\top}$ (Paucisalibacillus gen. nov.) with those of phylogenetically related genera of the family Bacillaceae

Genera: 1, Paucisalibacillus gen. nov.; 2, Salinibacillus (data from Ren \& Zhou, 2005); 3, Virgibacillus (Yoon et al., 2005; Lee et al., 2006); 4, Oceanobacillus (Lee et al., 2006); 5, Lentibacillus (Jeon et al., 2005). +, Positive result or growth; -, negative result or no growth; v, variable results between strains; ND, no data available. Members of all genera are catalase-positive.

\begin{tabular}{|c|c|c|c|c|c|}
\hline Characteristic & 1 & 2 & 3 & 4 & 5 \\
\hline $\mathrm{NaCl}$ requirement for growth & - & + & + & - & + \\
\hline $\mathrm{NaCl}$ optimum (\%) & 1 & $12-15$ & $4-10$ & 3 & $4-15$ \\
\hline Growth temperature range $\left({ }^{\circ} \mathrm{C}\right)$ & $20-45$ & $20-50$ & $5-50$ & $15-42$ & $15-40$ \\
\hline Oxidase & - & $\mathrm{V}$ & + & V & + \\
\hline DNase & + & - & + & - & ND \\
\hline \multicolumn{6}{|l|}{ Degradation/hydrolysis of: } \\
\hline Starch & + & $\mathrm{V}$ & $\mathrm{V}$ & - & - \\
\hline Aesculin & + & + & $\mathrm{V}$ & ND & $\mathrm{V}$ \\
\hline Tween 60 & + & - & $\mathrm{ND}$ & + & ND \\
\hline Tween 80 & + & - & $\mathrm{V}$ & $\mathrm{ND}$ & $\mathrm{V}$ \\
\hline Major fatty acids* & $\begin{array}{c}\text { ai-15:0, ai- } 17: 0 \\
\text { i- } 15: 0\end{array}$ & $\begin{array}{l}\text { ai-15:0, i-15:0, } \\
\text { ai-17:0, i-16:0 }\end{array}$ & $\begin{array}{c}\text { ai- } 15: 0, \text { i- } 15: 0 \\
\text { ai- } 17: 0\end{array}$ & $\begin{array}{l}\text { ai- } 15: 0, \mathrm{i}-15: 0, \\
\quad \text { ai- } 17: 0\end{array}$ & $\begin{array}{c}\text { ai- } 15: 0, \text { i- } 16: 0, \\
\text { ai- } 17: 0\end{array}$ \\
\hline Cell-wall type & $\mathrm{A} 4 \alpha$ & $\mathrm{A} 1 \gamma$ & $\mathrm{A} 1 \gamma$ & $\mathrm{A} 1 \gamma$ & $\mathrm{A} 1 \gamma$ \\
\hline
\end{tabular}

${ }^{\star}$ Anteiso- and iso-branched fatty acids are respectively indicated by ai and i.

Table 2. Fatty acid composition of strain $B 22^{\top}$ (Paucisalibacillus gen. nov.) and the type strains of species of the most closely related genera

Genera: 1, Paucisalibacillus (data for the type strain of the type species); 2, Salinibacillus (two species) (data from Ren \& Zhou, 2005); 3, Virgibacillus (ten species) (Yoon et al., 2005; Lee et al., 2006); 4, Oceanobacillus (three species) (Lu et al., 2001; Lee et al., 2006); 5, Lentibacillus (four species) (Jeon et al., 2005). Data are mean \pm SD percentages of each fatty acid. Abbreviations: i, iso; ai, anteiso; tr, trace $(<0 \cdot 5 \%) ;-$, not detected.

\begin{tabular}{|lccccc|}
\hline Fatty acid & $\mathbf{1}$ & $\mathbf{2}$ & $\mathbf{3}$ & $\mathbf{4}$ & $\mathbf{5}$ \\
\hline $\mathrm{i}-13: 0$ & $\operatorname{tr}$ & $\operatorname{tr}$ & $1 \cdot 2 \pm 0 \cdot 1$ & - & $\operatorname{tr}$ \\
ai-13:0 & $\operatorname{tr}$ & $\operatorname{tr}$ & $0 \cdot 4 \pm 0 \cdot 1$ & - & - \\
i- $14: 0$ & $1 \cdot 4$ & $2 \cdot 6 \pm 0 \cdot 1$ & $3 \cdot 3 \pm 1 \cdot 6$ & $5 \cdot 7 \pm 4 \cdot 1$ & $10 \cdot 5 \pm 4 \cdot 4$ \\
$14: 0$ & $0 \cdot 5$ & $0 \cdot 5 \pm 0 \cdot 1$ & - & $1 \cdot 6 \pm 2 \cdot 8$ & $\operatorname{tr}$ \\
i- $15: 0$ & $15 \cdot 4$ & $23 \cdot 2 \pm 6 \cdot 8$ & $26 \cdot 1 \pm 14 \cdot 2$ & $19 \cdot 1 \pm 14 \cdot 7$ & $7 \cdot 6 \pm 6 \cdot 2$ \\
ai-15:0 & $58 \cdot 9$ & $31 \cdot 5 \pm 10 \cdot 7$ & $39 \cdot 5 \pm 9 \cdot 3$ & $42 \cdot 6 \pm 15 \cdot 1$ & $35 \cdot 5 \pm 6 \cdot 8$ \\
$15: 0$ & - & - & $0 \cdot 5 \pm 0 \cdot 1$ & $0 \cdot 3 \pm 0 \cdot 5$ & $\operatorname{tr}$ \\
i-16:0 & $2 \cdot 5$ & $10 \cdot 9 \pm 1 \cdot 5$ & $6 \cdot 4 \pm 1 \cdot 3$ & $7 \cdot 0 \pm 3 \cdot 6$ & $25 \cdot 5 \pm 7 \cdot 1$ \\
$16: 0$ & $1 \cdot 1$ & $2 \cdot 3 \pm 1 \cdot 1$ & $0 \cdot 9 \pm 0 \cdot 2$ & $5 \cdot 8 \pm 7 \cdot 4$ & $1 \cdot 7 \pm 0 \cdot 8$ \\
i-17:0 & $1 \cdot 1$ & $7 \cdot 6 \pm 5 \cdot 4$ & $5 \cdot 0 \pm 2 \cdot 5$ & $2 \cdot 7 \pm 2 \cdot 3$ & $2 \cdot 4 \pm 1 \cdot 9$ \\
ai-17:0 & $18 \cdot 3$ & $21 \cdot 1 \pm 3 \cdot 7$ & $16 \cdot 0 \pm 10 \cdot 6$ & $12 \cdot 3 \pm 7 \cdot 0$ & $16 \cdot 2 \pm 6 \cdot 9$ \\
\hline
\end{tabular}




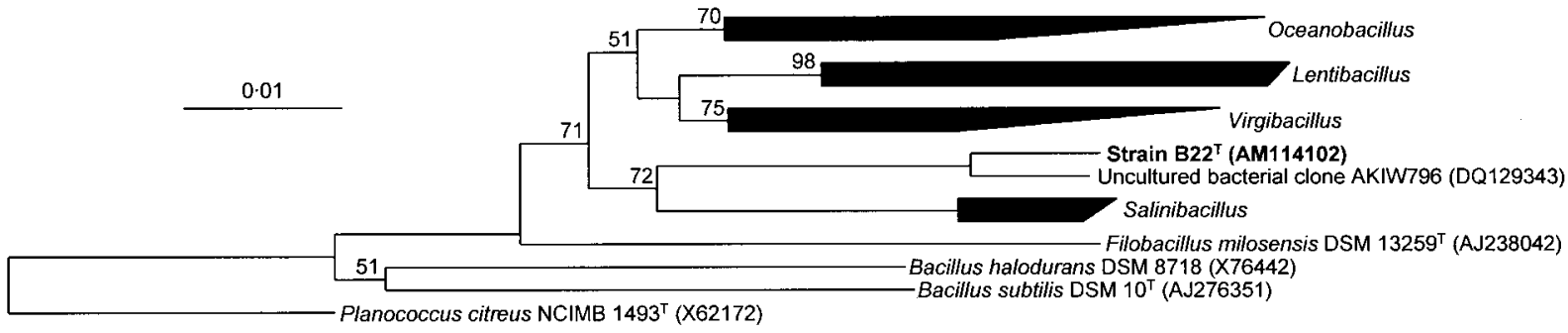

Fig. 1. Phylogenetic dendrogram based on a comparison of $16 \mathrm{~S}$ rRNA gene sequences of strain $B 22^{\top}$ and its closest phylogenetic relatives. The tree was created using the neighbour-joining method. Numbers on the tree indicate the percentages of bootstrap sampling, derived from 1000 replications. Besides those indicated, 16S rRNA gene sequences from strains of the following species were used to produce the tree (GenBank accession nos are given in parentheses): Salinibacillus aidingensis (AY321436), Salinibacillus kushneri (AY321437), Virgibacillus halodenitrificans (AY543168), Virgibacillus pantothenticus (AB039331), Virgibacillus marismortui (AJ009793), Virgibacillus proomii (AJ012667), Virgibacillus dokdonensis (AY822043), Virgibacillus salexigens (Y11603), Lentibacillus salarius (AY667493), Lentibacillus juripiscarius (AB127980), Lentibacillus salicampi (AY057394), Oceanobacillus iheyensis (AB010863), Oceanobacillus picturae (AJ315060) and Oceanobacillus oncorhynchi (AB188089). Bar, 1 inferred nucleotide substitution per $100 \mathrm{nt}$.

optimum temperature for growth is about $37^{\circ} \mathrm{C}$ and no growth occurs at 15 or $45^{\circ} \mathrm{C}$; the optimum $\mathrm{pH}$ is between $8 \cdot 0$ and $8 \cdot 5$ and no growth occurs at $\mathrm{pH} 6 \cdot 0$ or $9 \cdot 5$. Grows in $0-8 \% \mathrm{NaCl}$; optimal growth occurs in media containing $1 \%(\mathrm{w} / \mathrm{v}) \mathrm{NaCl}$. Predominant fatty acids are anteiso- $15: 0$, anteiso- $17: 0$ and iso- $15: 0$, which comprise over $90 \%$ of the total fatty acids. Hydrolyses casein, starch, DNA, arbutin, aesculin, hippurate, elastin, gelatin and Tweens 20, 40, 60 and 80. Xylan and urea are not hydrolysed. DNase is detected. Does not reduce nitrate. Assimilates glucose, mannose, galactose, fructose, L-sorbose, D-xylose, sucrose, maltose, lactose, trehalose, L-rhamnose, raffinose, L-fucose, ribitol, xylitol, L-erythritol, mannitol, 2-oxoglutarate, lactate, malate, pyruvate, acetate, L-glutamate, glycine, serine and threonine. Does not utilize arabinose, ribose, melezitose, cellobiose, melibiose, sorbitol, arabitol, myo-inositol, glycerol, succinate, citrate, aspartate, alanine, asparagine, cysteine, phenylalanine, histidine, isoleucine, lysine, methionine, proline, glutamine, arginine, valine or ornithine. Acid is produced from ribose, xylose, glucose, mannose, fructose, mannitol, $N$-acetylglucosamine, amygdalin, arbutin, salicin, cellobiose, maltose, sucrose, starch, glycogen, gentiobiose, turanose, tagatose and 5-ketogluconate, but not from the other substrates in the API $50 \mathrm{CH}$ test strips.

The type strain is $\mathrm{B} 22^{\mathrm{T}}\left(=\mathrm{CIP} 108857^{\mathrm{T}}=\mathrm{LMG} 23148^{\mathrm{T}}\right)$, isolated from potting soil. The DNA G $+\mathrm{C}$ content of strain $\mathrm{B} 22^{\mathrm{T}}$ is $37.9 \mathrm{~mol} \%$.

\section{Acknowledgements}

This research was funded in part by FCT/FEDER project POCTI/CED/ $34891 / 2000$ and by project POCTI/ESP/35761/2000. We thank Dr Peter Schumann (DSMZ, Germany) for determining peptidoglycan structure and Dra Fernanda Nobre (Universidade de Coimbra, Portugal) for helping in the FAME analysis. We are indebted to Dr Jean Euzéby (École National Vétérinaire, Toulouse, France) for the etymology of the name of the novel organism.

\section{References}

Edelstein, P. (1981). Improved semiselective medium for isolation of Legionella pneumophila from contaminated clinical and environmental specimens. J Clin Microbiol 14, 298-303.

Felsenstein, J. (1981). Evolutionary trees from DNA sequences: a maximum likelihood approach. J Mol Evol 17, 368-376.

Felsenstein, J. (1985). Confidence limits on phylogenies: an approach using the bootstrap. Evolution 39, 783-791.

Heyndrickx, M., Lebbe, L., Kersters, K., De Vos, P., Forsyth, G. \& Logan, N. A. (1998). Virgibacillus: a new genus to accommodate Bacillus pantothenticus (Proom and Knight 1950). Emended description of Virgibacillus pantothenticus. Int J Syst Bacteriol 48, 99-106.

Jeon, C. O., Lim, J. M., Lee, J. C., Lee, G. S., Lee, J. M., Xu, L. H., Jiang, C. L. \& Kim, C. J. (2005). Lentibacillus salarius sp. nov., isolated from saline sediment in China, and emended description of the genus Lentibacillus. Int J Syst Evol Microbiol 55, 1339-1343.

Lee, J.-S., Lim, J.-M., Lee, K. C., Lee, J.-C., Park, Y.-H. \& Kim, C.-J. (2006). Virgibacillus koreensis sp. nov., a novel bacterium from a salt field, and transfer of Virgibacillus picturae to the genus Oceanobacillus as Oceanobacillus picturae comb. nov. with emended descriptions. Int J Syst Evol Microbiol 56, 251-257.

Lu, J., Nogi, Y. \& Takami, H. (2001). Oceanobacillus iheyensis gen. nov., sp. nov., a deep-sea extremely halotolerant and alkaliphilic species isolated from a depth of $1050 \mathrm{~m}$ on the Iheya Ridge. FEMS Microbiol Lett 205, 291-297.

Ludwig, W., Strunk, O., Westram, R. \& 29 other authors (2004). ARB: a software environment for sequence data. Nucleic Acids Res 32, 1363-1371.

Mesbah, M., Premachandran, U. \& Whitman, W. B. (1989). Precise measurement of the $\mathrm{G}+\mathrm{C}$ content of deoxyribonucleic acid by high-performance liquid chromatography. Int J Syst Bacteriol 39, 159-167.

Ren, P. G. \& Zhou, P. J. (2005). Salinibacillus aidingensis gen. nov., sp. nov. and Salinibacillus kushneri sp. nov., moderately halophilic bacteria isolated from a neutral saline lake in Xin-Jiang, China. Int J Syst Evol Microbiol 55, 949-953.

Saitou, N. \& Nei, M. (1987). The neighbor-joining method: a new method for reconstructing phylogenetic trees. Mol Biol Evol 4, 406-425. 
Schleifer, K. H. (1985). Analysis of the chemical composition and primary structure of murein. Methods Microbiol 18, 123-156.

Schleifer, K. H. \& Kandler, O. (1972). Peptidoglycan types of bacterial cell walls and their taxonomic implications. Bacteriol Rev 36, 407-477.

Tiago, I., Mendes, V., Pires, C., Morais, P. V. \& Verissimo, A. (2005a). Phenylobacterium falsum sp. nov., an alphaproteobacterium isolated from a nonsaline alkaline groundwater, and emended description of the genus Phenylobacterium. Syst Appl Microbiol 28, 295-302.

Tiago, I., Pires, C., Mendes, V., Morais, P. V., da Costa, M. \& Veríssimo, A. (2005b). Microcella putealis gen. nov., sp. nov., a Gram-positive alkaliphilic bacterium isolated from a nonsaline alkaline groundwater. Syst Appl Microbiol 28, 479-487.
Tiago, I., Mendes, V., Pires, C., Morais, P. V. \& Verissimo, A. (2006). Chimaereicella alkaliphila gen. nov., sp. nov., a Gram-negative alkaliphilic bacterium isolated from a nonsaline alkaline groundwater. Syst Appl Microbiol 29, 100-108.

Tindall, B. J. (1989). Fully saturated menaquinones in the archaebacterium Pyrobaculum islandicum. FEMS Microbiol Lett 60, 251-254.

Yoon, J. H., Kang, K. H. \& Park, Y. H. (2002). Lentibacillus salicampi gen. nov., sp. nov., a moderately halophilic bacterium isolated from a salt field in Korea. Int J Syst Evol Microbiol 52, 2043-2048.

Yoon, J. H., Kang, S. J., Lee, S. Y., Lee, M. H. \& Oh, T. K. (2005). Virgibacillus dokdonensis sp. nov., isolated from a Korean island, Dokdo, located at the edge of the East Sea in Korea. Int J Syst Evol Microbiol 55, 1833-1837. 